\title{
Os artefatos laminares da coleção Indaiazinho e sua contribuição para a compreensão das ocupações Jê na história de Mato Grosso do Sul, Brasil
}

\author{
Rodrigo Luiz Simas de Aguiar ${ }^{1}$ \\ Renan Silva Martins ${ }^{2}$ \\ Luiz Fernando de Almeida Silva \\ Giovanni Radaelli Cenci \\ Universidade Federal da Grande Dourados
}

Resumo: O artigo traz as considerações e os resultados provenientes da análise da coleção de artefatos líticos "PCH Indaiazinho", que compõe a reserva técnica do Laboratório de Arqueologia da Universidade Federal da Grande Dourados. As peças da coleção foram analisadas em busca de vestígios que comprovassem sua utilização, para isso empregamos técnicas de reconhecimento dos possíveis estigmas. A partir da cerâmica pré-colonial da tradição Una, à qual o material lítico estava associado, sabemos que os remanescentes arqueológicos são produtos dos Jê pré-coloniais. A análise demonstrou que a produção de artefatos laminares era um elemento importante no modo de produção, relacionando-se não com a abertura de grandes áreas de cultivo, mas sim ao desbaste de arbustos e pequenas árvores que, provavelmente, serviriam para alimentar grandes fogueiras.

Palavras-chave: artefatos líticos; análise; arqueologia pré-colonial; Jê.

${ }^{1}$ Doutor em Antropologia pela Universidad de Salamanca com pós-doutoramento em Arqueologia Pré-histórica na Universidade de Coimbra. Coordenador do Laboratório de Arqueologia da Universidade Fed eral da Grande Dourados.

${ }^{2}$ Graduando do curso de História pela Universidade Federal da Grande Dourados. 


\title{
The blade type stone tools from Indaiazinho collection and their contribution to the study of Jê ocupation in the history of Mato Grosso do Sul, Brazil
}

\begin{abstract}
This paper brings the results from the analysis of the stone tools from "PCH Indaiazinho" collection that is part of the Archaeology Laboratory of Federal University of Grande Dourados. The tools were analyzed in searching for wear marks that proves their use. The Una pottery indicates that the stone tools was made by Prehistoric Je groups. The study demonstrate that the production of blade type tools was an important element in the production mode, not related to the cleaning of fields for farming but to the cut of bushes and small trees probably used to feed large bonfires.
\end{abstract}

Keywords: stone tools, analysis, prehistoric archaeology, Jê, Mato Grosso do Sul, Brazil.

\section{Los artefactos laminares de la colección Indaiazinho y su contribución pala la comprensión acerca de las ocupaciones Jê en la história de Mato Grosso do Sul, Brasil}

\begin{abstract}
Resumen: El artículo aporta los resultados provenientes del análisis de la colección de artefactos líticos "PCH Indaiazinho", que integran la reserva técnica del Laboratorio de Arqueología de la Universidad Federal da Grande Dourados. Las piezas de la colección fueron analizadas en busca por marcas que probasen la utilización y para eso empegamos las técnicas de reconocimiento de posibles estigmas. Considerando la cerámica precolonial de la tradición Una, a la cual el material lítico estaba asociado, sabemos que los restos arqueológicos son productos de los Jê precoloniales. El análisis ha demostrado que la producción de artefactos laminares era un elemento importante en el modo de producción, empleado no en la abertura de grandes áreas de cultivo, pero en la poda de carrascos y arboles pequeños que, muy probablemente, alimentaron grandes hogueras.
\end{abstract}

Palabras clave: artefactos líticos, análisis, arqueología precolonial, Jê, Mato Grosso do Sul, Brasil. 
este artigo discutiremos os resultados das análises do material proveniente da coleção Indaiazinho, que integra a reserva técnica do laboratório de arqueologia da Universidade Federal da Grande Dourados. A coleção Indaiazinho é formada por remanescentes arqueológicos provenientes do projeto de "Monitoramento do Patrimônio Arqueológico da Área sob Intervenção da PCH Indaiazinho”. O empreendimento se deu no município de Cassilândia, estado de Mato Grosso do Sul e a variável arqueológica ficou sob a responsabilidade da Ambiento Consultoria e Assessoria LTDA, tendo como arqueóloga responsável Camila Constantino Alves (ALVES, 2011).

A parcela analisada da coleção Indaiazinho é constituída por 282 peças, sendo 89 artefatos líticos, 189 fragmentos de cerâmica pré-colonial e 4 fragmentos de vidro contemporâneo. As atividades desenvolvidas em laboratório se concentraram exclusivamente na análise dos artefatos líticos da coleção, tendo por objetivo relacionar o contexto dos artefatos à ocupação pré-colonial da região do rio Indaiazinho, afluente do Rio Sucuriú.

A confirmação da presença do Jê arqueológico na porção leste do estado de Mato Grosso do Sul demonstra que estes grupos também estiveram presentes no contexto geográfico da Bacia do Paraná, ainda que seus sítios sejam predominantes na parte oeste do estado, na Bacia do Paraguai.

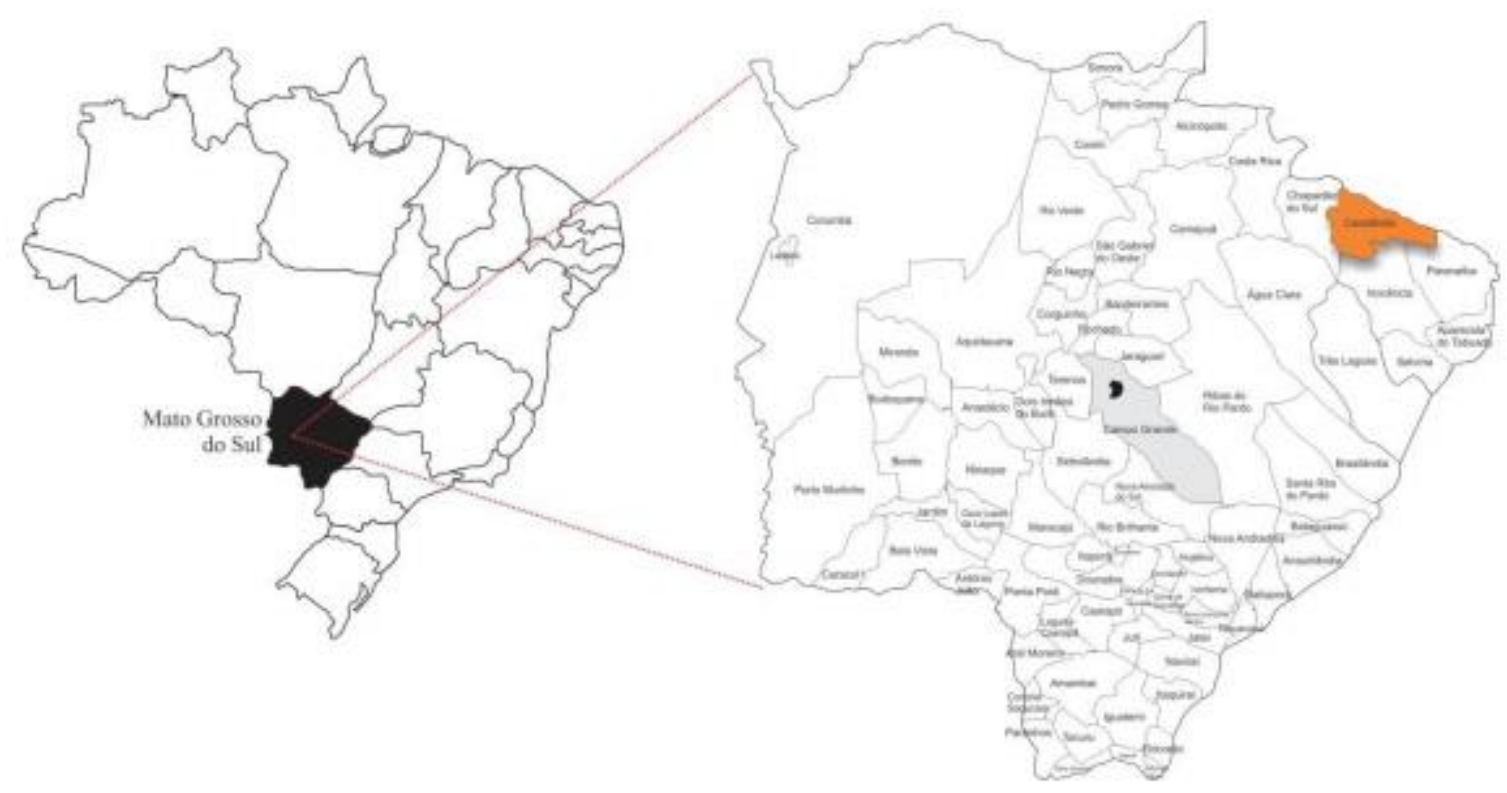



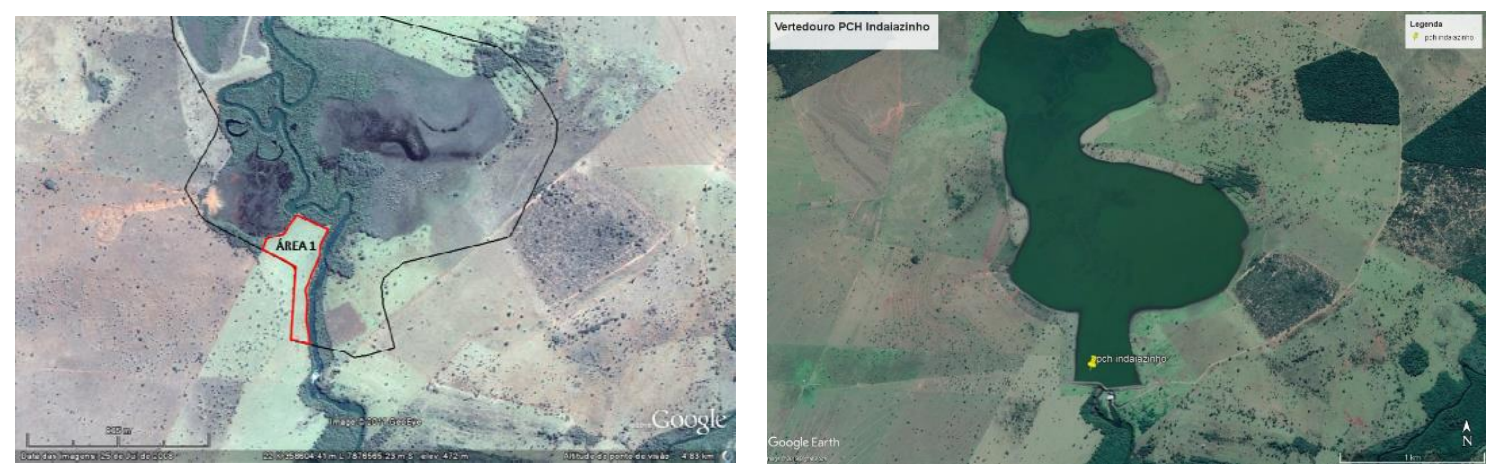

Figura 2. Previsão da Área de Impacto Direto do empreendimento (em ALVES, 2011) e, após a conclusão do empreendimento, a área diretamente impactada observada através do Google Earth.

Parte da cerâmica desta coleção apresenta características específicas da Tradição Una, permitindo estabelecer a conexão com os povos Jê pré-coloniais. Também os artefatos líticos laminares são indicadores da Tradição Una. Em nossa análise, focamos nos artefatos líticos, especialmente os laminares, como machados e raspadores. Para tanto, depositamos nossa atenção nas técnicas de lascamento empregadas na elaboração dos artefatos, bem como na identificação de estigmas de uso. Dentre os marcadores que indicam o uso do artefato, destaca-se o embotamento e os microlascamentos no gume.

Inspirados em Semenov (1973), entendemos que a utilização dos artefatos líticos para qualquer um dos diversos fins possíveis, deixa vestígios permanentes na ferramenta. Essas marcas são estudadas através da traceologia, que se ocupa de interpretar, a partir dos vestígios deixados nos artefatos líticos, para que e como foram utilizados esses artefatos. As bases dos estudos de técnicas para identificação de marcas de utilização nos artefatos líticos foram propostas por Semenov, em 1957 e, apesar de suas propostas já datarem de mais de meio século, são ainda muito relevantes para o estudo de artefatos arqueológicos em laboratório. $\mathrm{O}$ autor russo assevera que a utilização dos artefatos líticos deixa macro e micro estigmas, que são passíveis de investigação pelo arqueólogo, seja a olho nu ou com o auxílio de microscópio. O contato da superfície funcional de um artefato com outro objeto - seja cortando madeira, carneando carcaças ou qualquer outra atividade de uso - pode deixar vestígios indeléveis, sendo estes vestígios uma fonte de informação sobre as atividades humanas na pré-história. Em outras palavras:

\begin{abstract}
Durante o contacto, os bordos e superfícies sofrem modificações de natureza mecânica e de ordem química visíveis à escala microscópica. A cada material trabalhado e atividade efetuada correspondem vestígios de uso bem característicos, igualmente perceptíveis ao microscópio. Os estigmas de utilização conservados no objeto testemunham o gesto efetuado e a atividade que lhe está subjacente. A interpretação da função e das modalidades de utilização dos materiais arqueológicos é realizada com base nos vestígios de uso obtidos pela experimentação onde são reproduzidas as atividades pressupostamente efetuadas. (IGREJA et al., 2007: 19)
\end{abstract}

Tais pressupostos foram norteadores de nossas análises, para as quais fizemos uso de estereoscópio binocular com ampliação de 40 vezes ou de 80 vezes (dependendo do caso). Os resultados serão apresentados ao longo do texto. 


\section{Breve contexto arqueológico para as ocupações Jê na história de Mato Grosso do Sul}

Ainda que o início da ocupação humana no estado date entre 12 e 10 mil A.P. 3 , com o movimento de povos caçadores e coletores pelos campos do Brasil Central, já bem discutida na bibliografia científica (SCHMITZ, 1987; VERONEZE, 1992; SCHMITZ, 2005; MARTINS e KASHIMOTO, 2012; BUENO e DIAS, 2015; AGUIAR, 2016; AGUIAR e SOUZA, 2017), decidimos focar o contexto arqueológico diretamente no período de interesse para nosso estudo, quando das ocupações arqueológicas Jê. Em se tratando de povos Jê pré-coloniais, existe um grande vazio na produção científica de Mato Grosso do Sul. O pouco que sabemos vem de dados complementares de pesquisas cujo foco foram outras tradições arqueológicas. Aguiar et al. (2019) tentaram estabelecer um panorama para as ocupações da tradição Una ${ }^{4}$ em um texto que está em processo de publicação. Fora este, restam apenas alguns poucos artigos para ajudar a compreender o processo de ocupação Jê na história sul-mato-grossense (AGUIAR, 2017; AGUIAR et al., 2018). Assim sendo, entendemos que a construção de um panorama acerca da ocupação pré-colonial por povos Jê em Mato Grosso do Sul está ainda no início e que a carência de fontes é o maior desafio no momento.

Se usarmos a cerâmica Una como marcador para as ocupações Jê do Brasil Central, podemos estabelecer uma cronologia. A produção mais antiga deste tipo de cerâmica que se tem notícia data de 4 mil anos (PROUS, 1992). Em Mato Grosso do Sul, as ocupações Jê estão datadas em 3 mil anos (AGUIAR, 2016). Alguns autores propõem que os ceramistas Jê seriam a continuidade de grupos caçadores e coletores tardios que incorporaram a cerâmica ao seu horizonte tecnológico (WUST, 1990; MORALES, 2008). Os resultados das escavações da equipe espanhola do Museu de Altamira nos sítios paraguaios de Cerro Corá e Cerro Guazú também parecem sugerir este tipo de transição, com datas de 5.200 A.P. para a fase pré-cerâmica, aparecendo na sequência cerâmica datada em 3.215 A.P. (LASHERAS CORRUCHAGA et al., 2014).

Por volta de 3 mil anos atrás, os grupos Jê teriam iniciado suas migrações para as terras do sul do Brasil (URBAN, 1998; SCHMITZ e ROGGE, 2013). Deixando para trás os campos de cerrado, passam a se adaptar aos campos de araucárias, tendo a coleta do pinhão como atividade destacada. Já no litoral se tornam exímios pescadores, ocupando também as ilhas (AGUIAR, 2009). Isso demonstra a capacidade de adaptação destes caçadores e coletores ceramistas, assumindo novas práticas em face a outros ecossistemas, de forma a otimizar os modos de produção.

\section{Métodos e procedimentos de laboratório}

A coleção Indaiazinho é constituída por 89 artefatos líticos, divididos em raspadores, lâminas, lascas, estilhas, núcleos e machados de mão. Todas as peças foram produzidas em arenito silicificado, a exceção de uma peça em sílex e outra em granito. 


\begin{tabular}{|c|c|c|c|c|c|c|}
\hline Lâminas & Raspadores & \multicolumn{2}{c|}{ Machados de mão } & $\begin{array}{c}\text { Machado } \\
\text { polido }\end{array}$ & Núcleos & \multicolumn{2}{c|}{$\begin{array}{c}\text { Lascas } \\
\text { comuns }\end{array}$} & Estilhas \\
\hline 2 & 16 & 4 & 1 & 8 & 56 & 2 \\
\hline
\end{tabular}

Tabela 1. Distribuição morfo-tecnológica dos artefatos.

A primeira etapa foi a separação das peças em categorias e sua conferência com o livro tombo. Percebeu-se algumas incongruências na classificação feita durante a etapa de processamento, sendo estas corrigidas, com a formação de uma nova distribuição de categorias, cujo resultado está na tabela acima.

Após a distribuição das peças em categorias, partiu-se para a análise propriamente dita. Primeiramente, as peças foram analisadas a olho nu e por meio de lupa circular com iluminação artificial e aumento de cinco vezes. Já nesta etapa foi possível identificar estigmas de uso em algumas as peças, conforme descrito no item "Os artefatos laminares" deste artigo. Noutros casos, foi necessário empregar estereoscópio binocular com aumento de até 80 vezes.

Segundo Semenov (1973), há uma série de indícios a serem rastreados que podem representar estigmas de uso. O primeiro deles é a formação de uma linha ou de brilho ou de embotamento no gume, resultante da fricção do instrumento cortante sobre uma superfície menos resistente, como carne, fibras ou pele. Também se nota a perda da capacidade cortante, que fica muito evidente quando o objeto não é submetido a retoques. Há ainda a formação de microlascamentos nas arestas cortantes que ocorrem quando há grande pressão da mesma sobre a matéria a ser cortada. Machados, por exemplo, costumam apresentar este tipo de estigma que, em linhas gerais, constitui-se da expulsão de diminutas estilhas paralelamente à aresta cortante do artefato. Algumas lâminas, empregadas em atividades de grande pressão ou em materiais de maior resistência, também podem apresentar esta classe de estigma.

Quando a procura destes estigmas a olho nu não trouxe resultados, submeteu-se os artefatos à ampliação de 40 e até 80 vezes em estereoscópio. Houve alguns casos em que apenas quando o artefato foi submetido à ampliação é que se pôde registrar alguma classe de estigma de uso.

\section{Os artefatos laminares}

Por artefatos laminares entendemos todos os instrumentos produzidos com a finalidade de corte contendo, ao menos, uma aresta cortante ou gume. Estes gumes, sejam de machados, raspadores ou lâminas, seriam obtidos tanto pelo preparo da aresta cortante através de lascamento ou por intermédio do polimento. No caso da coleção analisada temos as duas categorias.

Os lascamentos empregados na produção dos artefatos analisados, via de regra, eram obtidos por percussão direta dura. Não notamos o emprego de lascamento bipolar, com uso de bigorna. Entre os artefatos laminares lascados, quando o gume apresentava perda de sua capacidade cortante, o mesmo poderia ser reavivado por meio de trabalho de retoque.

A maioria das peças da coleção Indaiazinho são descorticadas, predominando as lascas per se. Algumas lascas, apesar de morfologicamente ideais para serem utilizadas como raspadores, não apresentaram vestígios de utilização (seja em nível macro ou micro), levando-nos a considerar a possibilidade de que foram descartadas após o lascamento. 
As peças foram submetidas à análise em estereoscópio binocular com aumento de 40 ou 80 vezes (dependendo do caso), com o objetivo de se encontrar microlascamentos ou ranhuras de uso. Também foi utilizada lupa de aumento de cinco vezes, dotada de iluminação, pois a reflexão da luz da lupa sobre as peças torna possível identificar outros estigmas de uso, como o lustre ou o embotamento.

Para consolidar a metodologia de análise, seguiu-se os seguintes passos: a) classificação tipológica das peças; b) a identificação da matéria-prima; c) a verificação da presença, ou não, de estigmas de uso (macro ou micro); d) a identificação dos lascamentos e se houve retoque ou não.

Para classificar as lâminas de machados, foram utilizadas as definições presentes em Laming-Emperaire (1967) e Fernandes (2014).

\section{Lâminas de machado lascadas}

PEÇA IDZ oO4 - ferramenta de arenito silicificado, classificada como uma lâmina de machado lascada. Apresenta vestígios de trabalho em seu gume, porém, não foram notados vestígios de utilização. A peça foi trabalhada a fim de se criar uma aresta cortante (gume), isso é evidente por conta de uma série de pequenas retiradas executadas com essa finalidade. Uma curvatura acentuada próxima ao gume, que tornou a peça muito mais fina que o ideal, pode ter inviabilizado seu uso como machado de mão. A peça também demonstra negativos sobrepostos de lascamentos anteriores, e pelo menos 3 s equências de lascamento.

PEÇA IDZ o10 - é uma lâmina de machado de mão, lascada, em arenito silicificado. Apresenta vestígios de uso, tanto na forma de embotamento, como microlascamentos por toda a superfície do gume. Não aparenta trabalho de retoque. Há duas sequências de lascamentos presentes em duas faces diferentes, ambas sobrepostas, indicando retiradas anteriores. É possível notar uma grande faixa cortical em uma das faces.

PEÇA IDZ 11 - grande lasca, tipicamente conchoide, em arenito silicificado, classificada como lâmina de machado lascada. Seu uso seria na forma de machado de mão. Não apresenta vestígios de retoque, ou lascamentos posteriores. Possui estigmas de uso detectado pela presença de microlascamentos em uma parte do seu gume. A peça apresenta somente um negativo de lascamento em uma de suas faces. Há um pequeno resquício de córtex.

PEÇA IDZ 014 - machado polido de arenito silicificado, sendo o único artefato deste tipo em toda a coleção. Está fraturada na sua metade distal, com perda da parte onde se fixaria o cabo. Não foram notados claros estigmas de uso em seu gume, que está totalmente intacto. Há uma mossa em uma das faces, do tipo presente em quebra-coquinhos, o que pode indicar o emprego da peça para este fim após sua fratura.

PEÇA IDZ o89 - lâmina de machado lascada de arenito silicificado. Essa ferramenta foi remodelada a partir de um núcleo, sendo visível sua aparência bastante rudimentar. Apresenta estigmas de uso esparsos ao longo do gume. Por ser um núcleo reaproveitado é possível identificar uma serie de retiradas diferentes em suas faces. Há um enorme vestígio de córtex em uma das faces. 

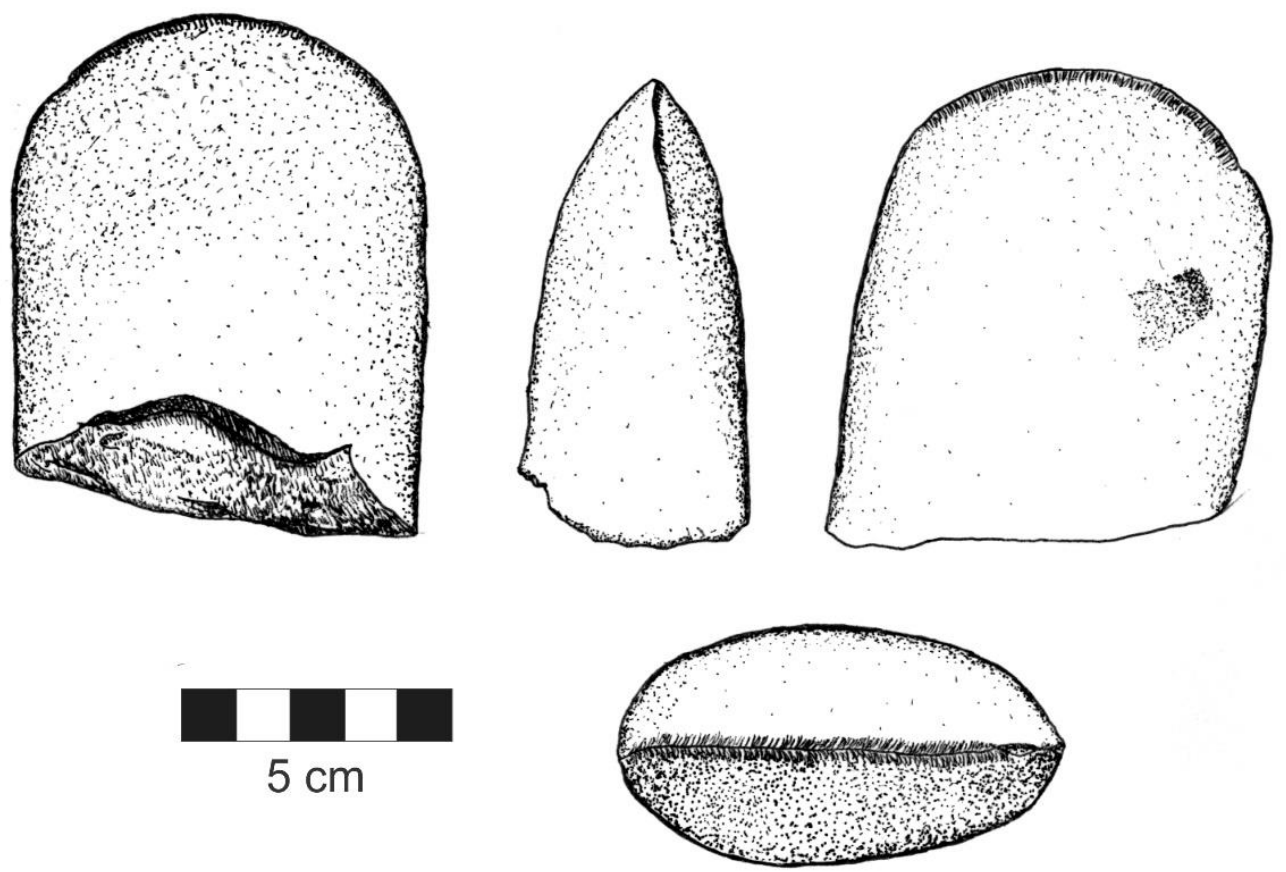

Figura 3 - Peça IDZ 14 - Lâmina de machado polido fraturado em sua metade distal destinada ao encabamento. Em uma de suas faces apresenta uma pequena mossa do tipo quebra-coquinho.

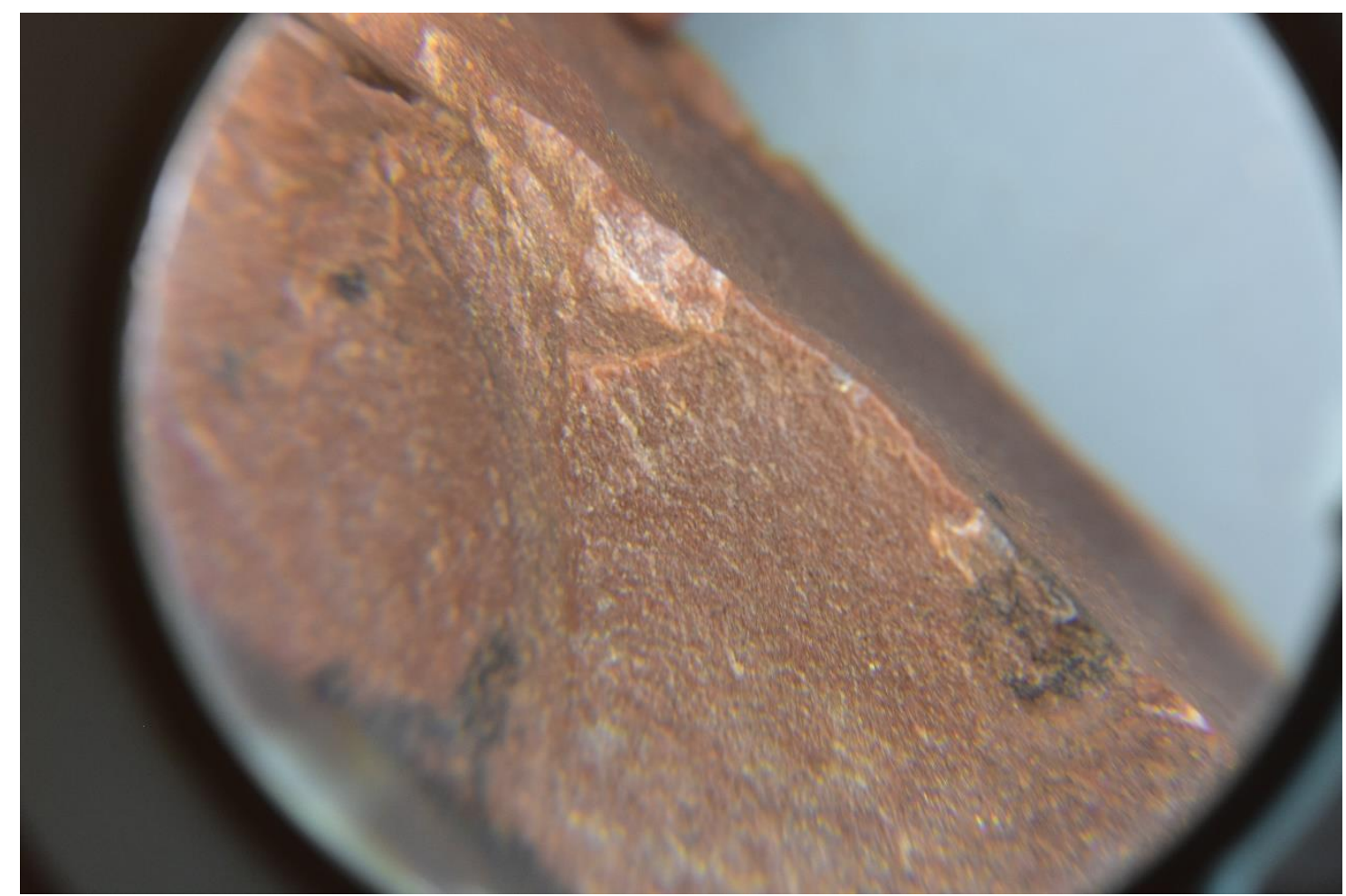

Figura 4 - Estigma de uso em forma de microlascamento. Peça IDZ o89. 


\section{Lâminas de corte}

PEÇA IDZ oo8 - lâmina em arenito silicificado. Apresenta sinais de uso visíveis a olho nu, na forma de microlascamentos em seu gume. Não apresenta retoque, porém uma provável aresta foi retirada para que a lâmina se tornasse ergonomicamente mais adequada para cortar.

PEÇA IDZ o12 - também lâmina em arenito silicificado, mas do tipo biface. Apresenta micro e macrolascamentos em um dos gumes, mas o outro está intacto. $\mathrm{O}$ dorso da peça mostra pelo menos quatro retiradas anteriores. Não há sinais de retoque ou trabalho posterior ao lascamento.

\section{Raspadores}

PEÇA IDZ 002 - raspador de arenito silicificado, que apresenta estigmas de uso na forma de microlascamentos em seu gume. A peça possui alguns negativos anteriores em seu dorso.

PEÇA IDZ 015 - também raspador em arenito silicificado. A peça apresenta vestígios de uso, na forma de microlascamentos, visíveis em microscópio. Morfologicamente é uma lasca do tipo conchoide com potencial cortante, indicando lascamento por percussão direta dura. O dorso mostra, pelo menos, quatro sequências de lascamento. Algo notável nessa peça é a matéria prima intrusiva no arenito silicificado, que a olho nu é percebida como uma variação de cor.

PEÇA IDZ o2o - este raspador em arenito silicificado apresenta estigmas de uso na forma de lustre e embotamento em seu gume. É possível notar também que passou por processo de reavivamento do gume por meio de novos lascamentos. É uma lasca tipicamente conchoidal, com apenas dois negativos em sua face dorsal e um na face ventral.

PEÇA IDZ o28 - raspador em arenito silicificado que apresenta macro-vestígios de utilização ao longo do gume, constituídos por pequenos lascamentos, ainda que escassos. Não apresenta marcas de retiradas anteriores.

PEÇA IDZ o44 - raspador em arenito silicificado com estigmas de uso visíveis a olho nu e microlascamentos visíveis a microscópio. É uma peça em formato tipicamente conchoide. Pode se notar lascamentos anteriores em sua face dorsal.

PEÇA IDZ 050-051 - raspador tipicamente conchoide, em arenito silicificado. Não apresenta vestígios de utilização. A peça está quebrada ao meio, o que pode indicar descarte por acidente de lascamento.

PEÇA IDZ 052 - este raspador em arenito silicificado possui estigmas de uso visíveis a olho nu, na forma de macro e microlascamentos ao longo do gume. Apresenta na face dorsal uma pequena retirada.

PEÇA IDZ o59 - o raspador, também em arenito silicificado, apresenta somente um macro vestigio de uso ao longo do gume, na forma de um pequeno 
lascamento. Também está fragmentada em uma parte mas, neste caso, pode ser que tenha se partido pelo uso.

PEÇA IDZ O6o - raspador com estigmas de uso na forma de microlascamentos ao longo de seu gume. É uma lasca conchoide, em arenito silicificado, resultante de lascamento por percussão direta dura. É possível notar estrias muito evidentes na superfície dorsal da lasca.

PEÇA IDZ 067 - apresenta lustre em seu gume como indicativo de uso. O gume foi retocado na tentativa de se renovar o potencial cortante. Morfologicamente constitui-se de lasca conchoide em arenito silicificado, resultante de percussão direta dura. Nota-se dois lascamentos anteriores em sua porção dorsal.

PEÇA IDZ 082 - tal e qual os demais casos, trata-se de um raspador em arenito silicificado. Há vestígios de microlascamentos ao longo do gume da peça, ainda que escassos. A ferramenta foi partida em ambas as extremidades e por isso aparenta uma forma "quadrada".

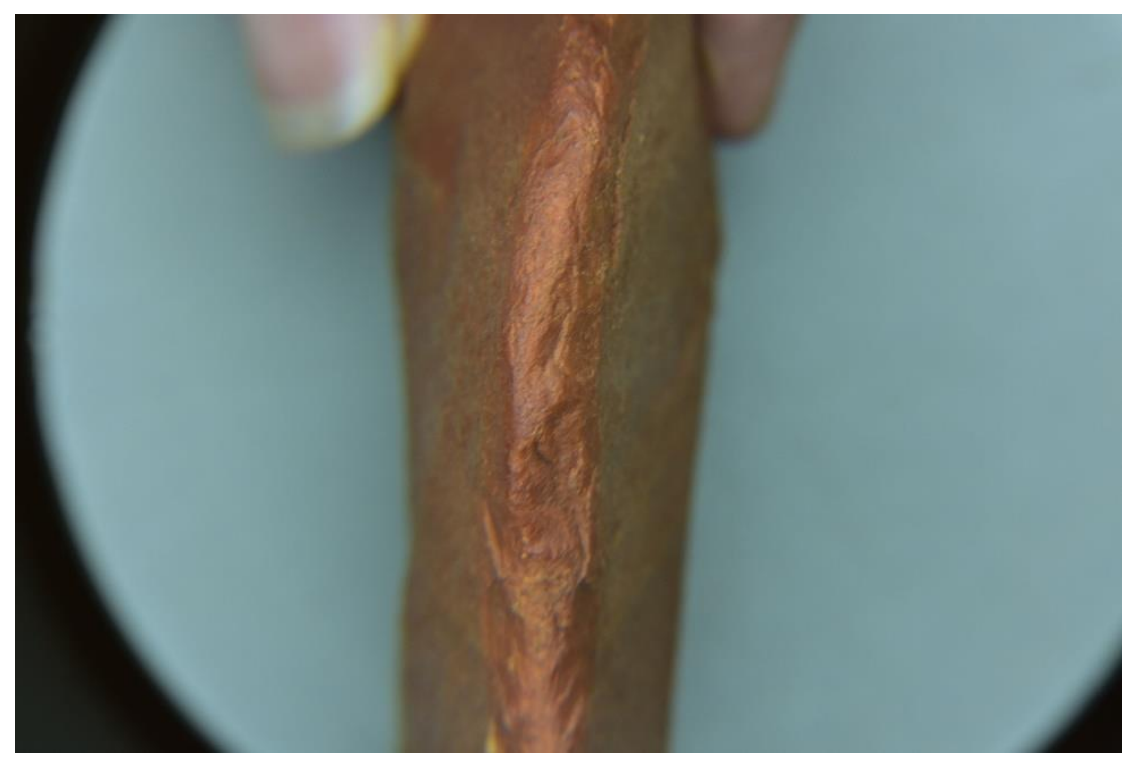

Figura 5. Raspador IDZ 20 com embotamento e desgaste do gume.

\section{Resultados}

Feitas as análises, concluímos que as peças da coleção Indaiazinho indicam que houve bastante investimento na produção de artefatos laminares. A maioria das peças estão na categoria das lascas per se, havendo pouca incidência de retoque. Ou seja, trata-se de lascas que em razão de seu potencial cortante foram utilizadas logo após sua remoção por percussão direta dura, sem retoques ou adaptações. A matéria prima que compõe a quase totalidade da coleção é o arenito silicificado.

A produção de machados, tanto os lascados de mão, como os polidos com encabamento, indica que a derrubada de árvores e arbustos era uma parte importante no modo de produção destes grupos. Partindo-se da hipótese de que os Jê arqueológicos no estado de Mato Grosso do Sul seriam caçadores e coletores que 
incorporaram a cerâmica em seu modo de produção, mas que não faziam uso (ao menos não constante) de agricultura (WUST, 1990; MORALES, 2008; e, posteriormente, AGUIAR, 2016; AGUIAR, 2017; AGUIAR et al., 2019), entende-se que a derrubada de árvores não estaria associada à formação de campos cultiváveis, mas sim à alimentação de grandes fogueiras, como foi confirmado no Templo dos Pilares5 (AGUIAR, 2016; AGUIAR e SOUZA, 2017).

No caso dos machados de mão, feitos em peças lascadas de arenito silicificado, ao voltarmos nossa atenção para o tamanho e forma - não são machados grandes e por isso impróprios para cortar árvores espessas - percebemos que seu emprego seria para derrubar ou desbastar arbustos e árvores de pequeno porte, reforçando a hipótese de captação de matéria-prima para alimentação de fogueiras.

A ocorrência em Cassilândia de cultura material associada, indubitavelmente, aos grupos Jê arqueológicos mostra que a presença destes caçadores e coletores ceramistas iria para além da Bacia do Paraguai, seu domínio habitual, entre abrigos e cavernas nas franjas de serra que se debruçam por sobre a planície pantaneira. Agora sabe-se que eles também ocuparam, ainda que com menor frequência e intensidade, áreas abertas na Bacia do Paraná, que normalmente são identificadas como domínios de outros grupos arqueológicos.

Recebido em 28 de maio de 2019.

Aprovado em 20 de janeiro de 2020.

\section{Referências}

AGUIAR, R. L. S. Proposições para uma interpretação da Arte Rupestre na Ilha de Santa Catarina e Adjacências, Brasil. CLIO. Série Arqueológica (UFPE), 24: 100-110, 2009.

AGUIAR, R. L. S. Templo dos Pilares, Alcinópolis. Dourados: Laboratório de Arqueologia da UFGD, 2016.

AGUIAR, R. L. S. Petroglyphs of Footprints in the Brazilian State of Mato Grosso do Sul: Genesis and Stylistic Diffusion. Acta Archaeologica, 88: 205-216, 2017.

AGUIAR, R. L. S.; REGONATO, D. K.; LOPES, A. P.; RAINERI OLIVEIRA, C. A. "Os grupos Jê na pré-história de Mato Grosso do Sul". In: VILAÇA, Raquel; AGUIAR, Rodrigo Simas (orgs.). (I)mobilidades na Pré-história. Pessoas, recursos, objetos, sítios e territórios. Coimbra: Editora da Universidade de Coimbra, 2019 (no prelo).

AGUIAR, R. L. S.; SOUZA, J. C. A Escavação no Sítio Arqueológico Templo dos Pilares e sua relação com a ocupação humana e a produção de arte rupestre em Mato Grosso do Sul. CLIO. Série Arqueológica (UFPE), 32: 118-138, 2017.

5 Sítio arqueológico localizado na cidade de Alcinópolis, norte de Mato Grosso do Sul. Trata-se do maior sítio de arte rupestre do estado. 
ALVES, C. C. Relatório: Resultado do Monitoramento do Patrimônio Arqueológico da Área sob Intervenção da PCH INDAIAZINHO, Município de Cassilândia, Estado de Mato Grosso do Sul. Belo Horizonte: Ambiento Consultoria e Assessoria LTDA, 2011.

BUENO, L.; DIAS, A. S. Povoamento inicial da América do Sul: contribuições do contexto brasileiro. Estudos Avançados, 29 (83): 119-147, 2015.

FERNANDES, L. A. "Possibilidades da análise tecnomorfológica das lâminas de machado lascadas de sítios da tradição Aratu na Bahia”. In: Lourdeau A., Viana S. A., Rodet M. J. Indústrias líticas na América do Sul - abordagens teóricas e metodológicas. Recife: Ed. UFPE, 2014. pp. 91-122.

IGREJA, M. A.; MORENO GARCÍA, M. \& PIMENTA, C. M. Um exemplo de abordagem experimental da interface Traceologia lítica/Arqueozoologia - esquartejamento e tratamento da pele de um corço (Capreolus capreolus) com artefactos de pedra lascada. Revista Portuguesa de Arqueologia, 10 (2): 17-34, 2007.

LAMING-EMPERAIRE, A. "Guia para o estudo das indústrias líticas da América do Sul”. In: Manuais de Arqueologia n. 2. Curitiba: CEPA, 1967.

LASHERAS CORRUCHAGA, J. A.; FATÁS, P.; MONTES, R.; MUÑOZ, E. Itaguy Guasú: un abrigo del arcaico en Amambay (Paraguay) con útiles planoconvexos y puntas bifaciales y con grabados abstractos y de pisadas. Cuadernos del Instituto Nacional de Antropología y Pensamiento Latinoamericano-Series Especiales 1 (2): 234-252, 2014.

MARTINS, G. R.; KASHIMOTO, E. M.12.ooo anos: Arqueologia do povoamento humano no nordeste de Mato Grosso do Sul. Campo Grande (MS): Life Editora, 2012.

MORALES, W. F. Brasil Central, 12.ooo anos de ocupação humana no médio curso do Rio Tocantins, TO. São Paulo: Annablume, 2008.

PROUS, A. Arqueologia Brasileira. Brasília: UnB, 1992.

SCHMITZ, P. I. Prehistoric Hunters and Gatherers of Brazil. Journal of world Prehistory, 1 (1): 53-126, 1987.

SCHMITZ, P. I. Arqueologia do Estado do Mato Grosso do Sul. Palestra de abertura do XIII Congresso da Sociedade de Arqueologia Brasileira. São Leopoldo: IAP/Unisinos, 2005. Disponível em: http://www.anchietano.com.br.

SCHMITZ, P. I.; ROGGE, J. H. Pesquisando a trajetória do Jê meridional. Pesquisas, Série Antropologia, 70: 7-33, 2013.

SEMENOV, S. A. Prehistoric Technology. Bath: Adams \& Dart, 1973.

URBAN, G. "A história da cultura brasileira segundo as línguas nativas”. In: CARNEIRO DA CUNHA, Manuela. História dos Índios do Brasil. São Paulo: Companhia das Letras, 1998. pp. 87-102.

VERONEZE, E. A ocupação do Planalto Central Brasileiro: o nordeste do Mato Grosso do Sul. Dissertação de Mestrado. São Leopoldo: Unisinos, 1992.

WÜST, I. Continuidade e mudança: para uma interpretação dos grupos ceramistas pré-coloniais da bacia do rio Vermelho, Mato Grosso. Tese de Doutorado em Antropologia Social. São Paulo: USP, 1990. 